\title{
An empirical research on selecting the targeted suppliers and purchasing process of supermarket
}

\author{
Thanh-Tuyen Tran* \\ Scientific Research Office, Lac Hong University, Bien Hoa city, Dong Nai, Vietnam
}

\section{A R T I C LE IN F O}

\section{Article history:}

Received 3 November 2016

Received in revised form

3 March 2017

Accepted 10 March 2017

\section{Keywords:}

Big C Hanoi

Vietnam

Analytic hierarchical process

Expert

Supplier selecting

\begin{abstract}
A B S T R A C T
Retailing is a very special sector because it demonstrates the effectiveness of combined products and services to create business value. Moreover, this process is complicated, which may cause the problems in retailing and purchasing procedure. Thus, the purpose of this study is to integrate the Delphi method and fuzzy Analytic Hierarchical Process (AHP) to investigate the particular areas of purchasing process in Big C (Hanoi-Vietnam) which may require a high standard to select and investigate. The purchasing product, which is the brands instant coffee, is selected as the main focus during the research. The data was collected by experts of Big $C$ supermarket, which first go through the Delphi method to choose criteria and sub-criteria for the AHP. After a long process of calculation based on AHP, we have chosen the final supplier according expert's interview; Trung Nguyen is the most potential candidate to be the main supplier of instant coffee to Big C. The next priority should be Vina Café, NesCafe, Starbucks and G8 Coffee. By this paper, the researchers would contribute to the purchasing process of the supermarket, in general, and the special case of Big $\mathrm{C}$ a very modern model to apply, then to choose the right partner, not only for instant coffee industry but it can be applied for a lot of industries to the supermarkets.
\end{abstract}

(C) 2017 The Authors. Published by IASE. This is an open access article under the CC BY-NC-ND license (http://creativecommons.org/licenses/by-nc-nd/4.0/).

\section{Introduction}

Retailing is the act of selling goods or commodities in small quantities directly to consumers. These items are purchased from the manufacturers or wholesalers and sold to the end users at a marked up price. Retailing is a very special sector because it demonstrates the effectiveness of combined products and services to create business value.

To be survived in competitive market, retailers have to face to many pressures coming both from consumers and competitors (Hawkins et al., 2013). Firstly, the pressure coming from customers which includes wisely offering them discounts and satisfactorily accepting their bargains for a better consuming price is considered as one of the most important elements in successfully operating business. However, bargain prices itself partly contribute to create fierily competition between suppliers and decrease that business profit. Besides,

\footnotetext{
* Corresponding Author.

Email Address: copcoi2@gmail.com

https://doi.org/10.21833/ijaas.2017.04.015

2313-626X/C 2017 The Authors. Published by IASE.

This is an open access article under the CC BY-NC-ND license

(http://creativecommons.org/licenses/by-nc-nd/4.0/)
}

the improvement of human beings' lives standard makes their shopping needs increased and this leads to the mass new born of supermarkets. The more supermarkets are rushed into opening to adapt marketing need, the more retail choosing customers can make. This reinforces business bargaining position for a perfect and stable service quality, and a cheaper provider of goods as well.

Businesses exist in a competitive environment, so that competitors have put strong pressures on retail stores. Traditionally, the criterion for consumer selects retailer is often based on quality of goods or service and price. The cheapest but highest goods/service and price is usually selected without taking into consideration the additional costs. Actually, the competition between retailers makes threats against the existence of business themselves. On the other hand since 01/01/2009, Vietnam's retailing market start to opening under the WTO's commitment. According to the rules, enterprises with $100 \%$ capital of foreign investors are being allowed to participate into Vietnamese retailing market. In this context, how can local retail enterprises survive?

As a result of an unsuccessful choice of supplier, retailers may be faced with a risk of damaging their store image (Pope et al., 2012). For these reasons, 
making a right decision in supplier selection is very important for the retail enterprises. The analysis of criteria for selection and measuring the performance of supplier has been the focus of many academicians and purchasing practitioners since the 1960s. During recent years, the supplier/vendor selection process has received significant attention in the business management literature (Verma and Pullman, 1998). The paper aims to present the application of the Analytic Hierarchy Process (AHP) method in evaluation and selection of suppliers for Big C enterprise in Vietnam.

In this research, the authors want to investigate the particular areas of purchasing process in Big $C$ (Hanoi-Vietnam). The purchasing product, which is the brands instant coffee, is selected as the main focus during the research. This paper's research objectives are stated as follows: First, the authors determinate the process of purchasing product/service existing in Big $\mathrm{C}$ enterprise. As a practical application, the author applies AHP method in a real company, i.e. Big C. The purpose of the current study is to improve purchasing process. Enterprise will be evaluated by a high quantitative tool to make a concise comparison of suppliers' service quality. With an accurate result of choosing vendors, company can make good selecting decision to meet rigorous requirements from the competition and satisfied consumers' expectation. To contribute to academic field, the author chooses Big C enterprise as a case study to test a model of evaluating and selecting suppliers. Besides, through various comparable methods to make decisions presented in this study, the author can determine weak points and strong points of each method, including AHP.

The research method was applied in this research includes:

(1) Research discovery: to explore preliminary research issues that need as well as claims the research problem.

(2) Method of describing and comparing or the method of decision-making.

(3) Method of intergrated analysis towards the problem of assessing the quality and selecting suppliers for the enterprise Big C.

(4) Qualitative amd expert methods: to review evaluation criteria for selecting suppliers.

(5) Quantitative research method: Collecting information and data in quantitative form. This method is used in the process of applying AHP to evaluate and select suppliers for Big C.

(6) Data are collected through the process of interviewing representatives of 05 selected suppliers; Bic C chief executive, managers and staff; practicing outdoor activities; company file documents; journal and newspapers.

The research process is carefully presented in Fig. 1.

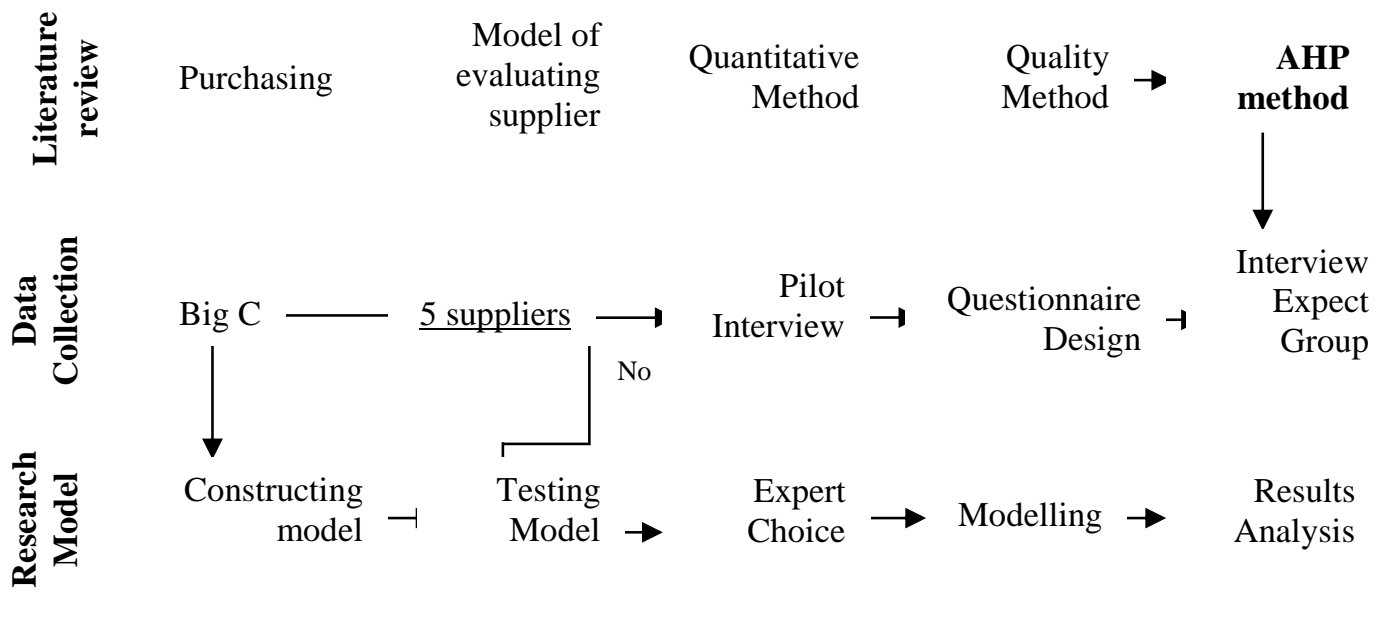

Conclusion Suggestion Limitation Future

Fig. 1: Research process

\section{Literature review}

\subsection{Definitions of purchasing}

Purchasing is defined as the activities of acquiring goods or services to accomplish the goals of an organization (Lysons, 1996). Purchasing is the strategic part of buying a good or a service, while procurement is considered as the fulfilment of orders to secure daily's operations. Therefore, procurement normally depends on purchasing.

\subsection{Characteristics of purchasing}

In the study of Baily et al. (2005), the major characteristics of purchasing are to: (1) maintain the quality and value of a company's products; (2) minimize cash tied-up in inventory; (3) maintain the flow of inputs to maintain the flow of outputs; and 
(4) strengthen the organization's competitive position.

\subsection{Models of evaluating and selecting supplier}

Chan et al. (2008) mentioned about five factors that influenced on the process of evaluating and selecting suppliers for business:

1. Cost (product price, freight costs, tariffs and customs duties)

2. Service quality (rejection rate of products, increase in delivery time, quality assessment, overcoming quality problem)

3. Delivery schedule $(R \& D$, reacts to the changes, the ease of communication)

4. Vendors' profiles (financial status, customer base, performance history, production facilities and capacity)

5. Risk factors (geographical location, political stability, economic terrorism)

In addition, in another study conducted by Sevkli et al. (2007), they considered the analytic hierarchy process, known as AHP method, as a successful one in evaluating and selecting vendors for entrepreneurs. Six criteria which stated by Sevkli et al. (2007) includes:

1. Performance evaluation (shipment, delivery, cost)

2. Human resources (quantity of staff, organizational structure, training, technicians quantity)

3. Quality of the evaluation system (management style, inspection and control, quality planning, quality assurance)

4. Production (production capacity, maintenance, lead time, updated, stored and development)

5. Criteria business (reputation, location, prices, patents, technical ability) information technology (RFID, EDI, Internet) Yang and Chen (2006) have supported the study of Sevkli et al. (2007) by confirming the successful of AHP method in evaluating and selecting vendors with quantitative and qualitative criteria (Table 1).

Similarly, Chavan (2009) pointed out six criteria to evaluate suitable vendors, which is admitted as one of the most modern method for the process of selecting supply chains for business and published worldwide in the report "Balance Score Card" (Table 2).

Table 1: Quantitative and qualitative criteria in evaluating and selecting vendors

\begin{tabular}{cc}
\hline Qualitative criteria & Quantitative criteria \\
\hline Service quality & Profit \\
Financial status & Cost \\
Customer service & Delivery \\
Production Capability & Space and distance \\
design and engineering & Information Technology \\
capabilities & Systems \\
\hline
\end{tabular}

\subsection{Function of AHP}

AHP was implemented to help decision maker to choose the best solution among several alternatives across multiple criteria. It uses the judgments of decision makers to form a decomposition of problems into hierarchies. Problem complexity is represented by the number of levels in the hierarchy which combine with the decision-makers model of the problem to be solved (Saaty, 1999). The hierarchy, as shown in Fig. 2, is used to derive ratioscaled measures for decision alternatives and the relative value that alternatives have against organizational goals (customer satisfaction, product/service, financial, human resource, and organizational effectiveness) and project risks. AHP uses matrix algebra to sort out factors to arrive at a mathematically optimal solution and derives ratio scales from paired comparisons of factors and choice options. AHP consists of four steps (Faisal and Banwet, 2008).

In the first step, the author defines the problem and state the goal or objective. In part two, the criteria or factors that influence the goal are made clear. In this step, the structure of these factors into levels and sublevels are also formed. In part three, the author uses paired comparisons of each factor with respect to each other that forms a comparison matrix with calculated weights, ranked eigen values, and consistency measures. In the final step, synthesize the ranks of alternatives until the final choice is made.

Table 2: Balance score

\begin{tabular}{|c|c|}
\hline Criteria & Factor \\
\hline Financial Health & $\begin{array}{c}\text { Revenue } \\
\text { Profit } \\
\text { Liquidity } \\
\text { ROI } \\
\text { Debt } \\
\text { Financial Transparency }\end{array}$ \\
\hline Expertise & $\begin{array}{l}\text { Capacity building network- } \\
\text { Technical capability } \\
\text { Technical creation ability } \\
\text { Investment in R \& D }\end{array}$ \\
\hline Operational Performance & $\begin{array}{l}\text { Delivery product on time } \\
\text { Lead-time } \\
\text { Responsiveness } \\
\text { Management and inventory } \\
\text { control } \\
\text { Facility maintenance } \\
\text { Forecasting capacity }\end{array}$ \\
\hline $\begin{array}{l}\text { Business Process and } \\
\text { Practices }\end{array}$ & $\begin{array}{c}\text { Service quality in exchange } \\
\text { value } \\
\text { Creating value in use } \\
\text { Operating business responsibly }\end{array}$ \\
\hline Behavior and Cultural Factor & $\begin{array}{c}\text { Racism } \\
\text { Business ethnic } \\
\text { Improvement } \\
\text { Updating information } \\
\text { frequently } \\
\text { Honesty }\end{array}$ \\
\hline Risks Factor & $\begin{array}{l}\text { Political situation } \\
\text { Natural condition } \\
\text { Stable economy } \\
\text { Insurance } \\
\text { Commercial law }\end{array}$ \\
\hline
\end{tabular}




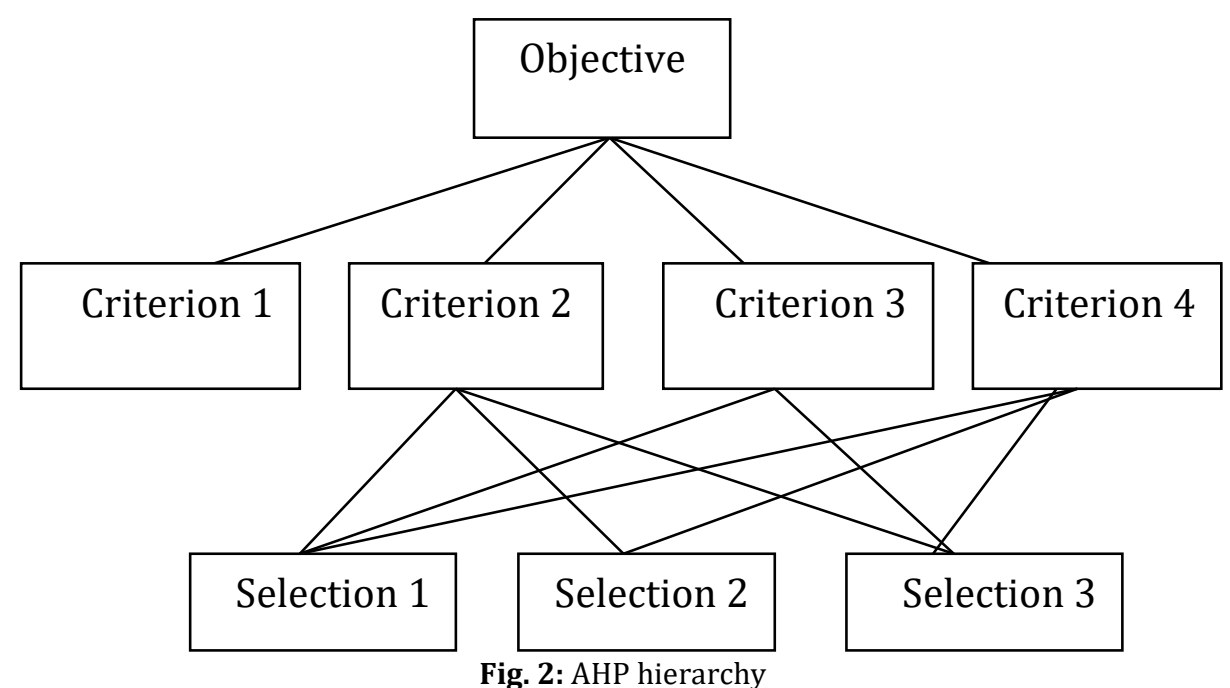

\subsection{AHP basic scales}

The paired comparison scales between the comparison pair (aij) of two items (item i and item j) is as follows:

(item i) 9-8-7-6-5-4-3-2-1-2-3-4-5-6-7-8-9 (item j)

The preference scale for pair-wise comparisons of two items ranges from the maximum value 9 to $1 / 9$ (0.111 in decimal from). Let aij represent the comparison between item-i (left) and item-j (right). If item-i is 5 times (strong importance) more important than item-j for a given criteria or product, then the comparison aji $=1 / a i j=1 / 5(0.200)$ or the reciprocal value for the paired comparison between both items.

After the comparison matrix is formed, AHP terminates by computing an eigenvector (also called a priority vector) that represents the relative ranking of importance (or preference) attached to the criteria or objects being compared. The largest eigenvalue provides a measure of consistency. Consistency is a matrix algebraic property of cardinal transitivity where the equality a(ij) $=1 / \mathrm{a}(\mathrm{ji})$ $=\mathrm{a}(\mathrm{ji})-1$, and $\mathrm{a}(\mathrm{ij})=\mathrm{a}(\mathrm{ik}) \mathrm{a}(\mathrm{kj})$ for any index $\mathrm{i}, \mathrm{j}, \mathrm{k}$. Inconsistencies arise if the transitive property is not satisfied as determined when the largest eigenvalue from the comparison matrix far exceeds the number of items being compared. The AHP preference scale shows in Table 3 to form the comparison matrices (Saaty, 1999).

Table 3: Preferences made on 1-9 scale

\begin{tabular}{ccc}
\hline $\begin{array}{c}\text { AHP Scale of Importance } \\
\text { for comparison pair (Aij) }\end{array}$ & $\begin{array}{c}\text { Numeric } \\
\text { Rating }\end{array}$ & $\begin{array}{c}\text { Reciprocal } \\
\text { (decimal) }\end{array}$ \\
\hline Extreme Importance & 9 & $1 / 9(0.111)$ \\
Very strong to extremely & 8 & $1 / 8(0.125)$ \\
Very strong importance & 7 & $1 / 7(0.143)$ \\
Strongly to very strong & 6 & $1 / 6(0.167)$ \\
Strong Importance & 5 & $1 / 5(0.200)$ \\
Moderately to Strong & 4 & $1 / 4(0.250)$ \\
Moderate Importance & 3 & $1 / 3(0.333)$ \\
Equally to Moderately & 2 & $1.2(0.500)$ \\
Equal Importance & 1 & $1(1.000)$ \\
\hline
\end{tabular}

The Geometric Mean is an alternative measure of the Priority and was formed by taking the $n$-th root of the product matrix of row elements divided by the column sum of row geometric means. The Geometric Mean agrees closely with the Priority.

Lambdamax (4.2385) is an eigenvalue scalar that solved the characteristic equation of the input comparison matrix. Ideally, the Lambdamax value should equal the number of factors in the comparison $(\mathrm{n}=4)$ for total consistency.

The consistency index (ci) measures the degree of logical consistency among pair-wise comparisons. The random index (ri) is the average CI value of randomly-generated comparison matrices using Saaty's preference scale (Table 3) sorted by the number of items being considered. If $|\mathrm{CI}|<0.05$, it shows good consistency of pair-wise comparisons. If $|\mathrm{CI}|>0.051$ means the pair-wise comparison should be revised.

$\mathrm{CI}=\frac{(\lambda \max -\mathrm{n})}{(\mathrm{n}-1)}$

Consistency ratio (cr) indicates the amount of allowed inconsistency $(0.10$ or $10 \%)$. Higher numbers mean the comparisons are less consistent. Smaller numbers mean comparisons are more consistent. CRs above 0.1 means the pair-wise comparison should be revisited or revised.

$\mathrm{CR}=\frac{|\mathrm{CI}|}{\mathrm{RI}}$

RI index is shown at Table 4 (Saaty, 2000). The Priority eigenvectors for each criterion were appended into a single, priority-weight matrix. Matrix multiplication of the priority-weight matrix and the criteria-comparison matrix eigenvector produced final result and benefit vectors.

\section{Case application}

\subsection{Traditional method to evaluate and to select right supplier of Big C}

The assessment suppliers of 'Big C' are mostly qualitative, personal, and done without expertise, so 
greatest weaknesses are laden subjective elements and/or emotions which may cause bias. The criteria to be used include:

1. Factors of providers' capacity: core competencies, financial, manufacturing technology, freight, providers assessing of how many cars and/or including any vehicles.
2. Criteria of delivery time: the operation, the time of deliveries, and/or how to transfer.

3. Experience: list of customers, the growth of these customers.

5. Time of payments: to pay the supplier till the end of each month and this demonstrate financial strength of the provider and their liquidity.

Table 4: RI index

\begin{tabular}{|c|c|c|c|c|c|c|c|c|c|c|c|c|c|c|c|}
\hline $\mathrm{n}=$ & 1 & 2 & 3 & 4 & 5 & 6 & 7 & 8 & 9 & 10 & 11 & 12 & 13 & 14 & 15 \\
\hline $\mathrm{RI}=$ & 0.00 & 0.00 & 0.58 & 0.90 & 1.12 & 1.24 & 1.32 & 1.41 & 1.45 & 1.49 & 1.51 & 1.48 & 1.56 & 1.57 & 1.59 \\
\hline
\end{tabular}

6. Risk: to find out whether providers have met with problems or difficulties.

7. Ability to transport typically increases the number of time from e.g. 1 time per day to 2 or 3 times per day to ensure sufficient supplying to meet customer demands during Chinese New Year and other special occasions.

8. Cultural practices i.e. some cases as the drivers are specifically polite and honest.

9. As loyal suppliers, the criteria are very highly.

10. The providers sympathize with difficulties of clients and are willing to share with clients.

According to Faisal and Banwet (2008), the process of evaluating several vendors' bias is in a qualitative sense. The level of application tools and quantitative methods is low. Therefore, Big $\mathrm{C}$ has adopted many applications but not yet supported software evaluation, and comparison suppliers. The decision support system has not been promoting in use. Therefore, the analysis in decision-making process has not yet been deep. The major management decisions are still based on personal experience. Thus, they need a professional method to select the right suppliers, not only based on their experience but also on the deep analysis, and AHP can meet their current demand and solve their problems.

\subsection{The top target in AHP}

The target is to select the main supplier of instant coffee to Big C. The goal of the research is carried out by analyzing the hierarchy and to study how $\mathrm{C}$ compares between different providers. Aims for the calculation process hierarchy analysis are to identify the best provider based on overall performance compared to other providers. Then we will use the results to analyze the data to understand why vendors have lower scores than the other vendors and what kind of improvements can be done to improve the weaknesses of the supplier.

Table 5 shows us the definitions selection perspectives (level 1) of AHP model.

Moreover, their sub-criteria are illustrated in Fig. 3 and Table 6.

These six criteria include Financial Capacity, Operational Performance, Expertise, Business Process \& Practice, Behavioral \& Cultural Practice, and Risk Elements. They are very important elements for any company to consider a partner or supplier to fulfill. They are surveyed and wellselected by the experts listed in Table 6 and Table 7 .

General introduction about suppliers of "Instant Coffee" was taken from the current names of instant coffee makers; these following suppliers are qualified by asking experts in this area (Table 8).

The process hierarchy analysis is a new way to measure supplier performance instant coffee industry of Big C. This is a new method to search for suppliers under its key ideas are comparing the performance of the supplier together. In this way, the results of the analysis hierarchy are a table which shows clearly the strong and weak suppliers. This important measure similar to the performance of the supplier is to be analyzing the factors behind this result and will be implemented in the next section.

\subsection{The process to select the right target of the AHP method}

This section presents the process according to the method of calculation process of AHP. Start with a hierarchical diagram level six main criteria governing the evaluation of suppliers' Instant coffee industry (Fig. 4).This matrix shows the relationship between the main criteria according to the scale of the AHP. Based on this table can determine the correlation between the level of importance of the variables.

Table 5: Definitions selection perspectives (Level 1)

\begin{tabular}{cc}
\hline Perspectives (Level 1) & Descriptions (Chan et al., 2008; Sevkli et al., 2007; Yang and Chen, 2006; Gorgieva-Trajkovska et al., 2016). \\
\hline Financial Capability & The stability of the business through providing indicators and financial statements. \\
Operational Performance & Ensuring that supplying always meets customer needs \\
Expertise & Ensuring stable, and capable of producing and trading. \\
$\begin{array}{c}\text { Business Process \& Practice } \\
\text { Behavioural \& Cultural Practice }\end{array}$ & $\begin{array}{c}\text { Ensuring the stability of the manufacturing process, business and cooperation between the two sides. } \\
\text { This factor affects only reach moderate under current evaluation of four experts. }\end{array}$ \\
Risk Elements & $\begin{array}{c}\text { These factors should be monitored through a collaborative process to be analyzed whether low risk factors } \\
\text { would make customers confident. }\end{array}$ \\
\hline
\end{tabular}



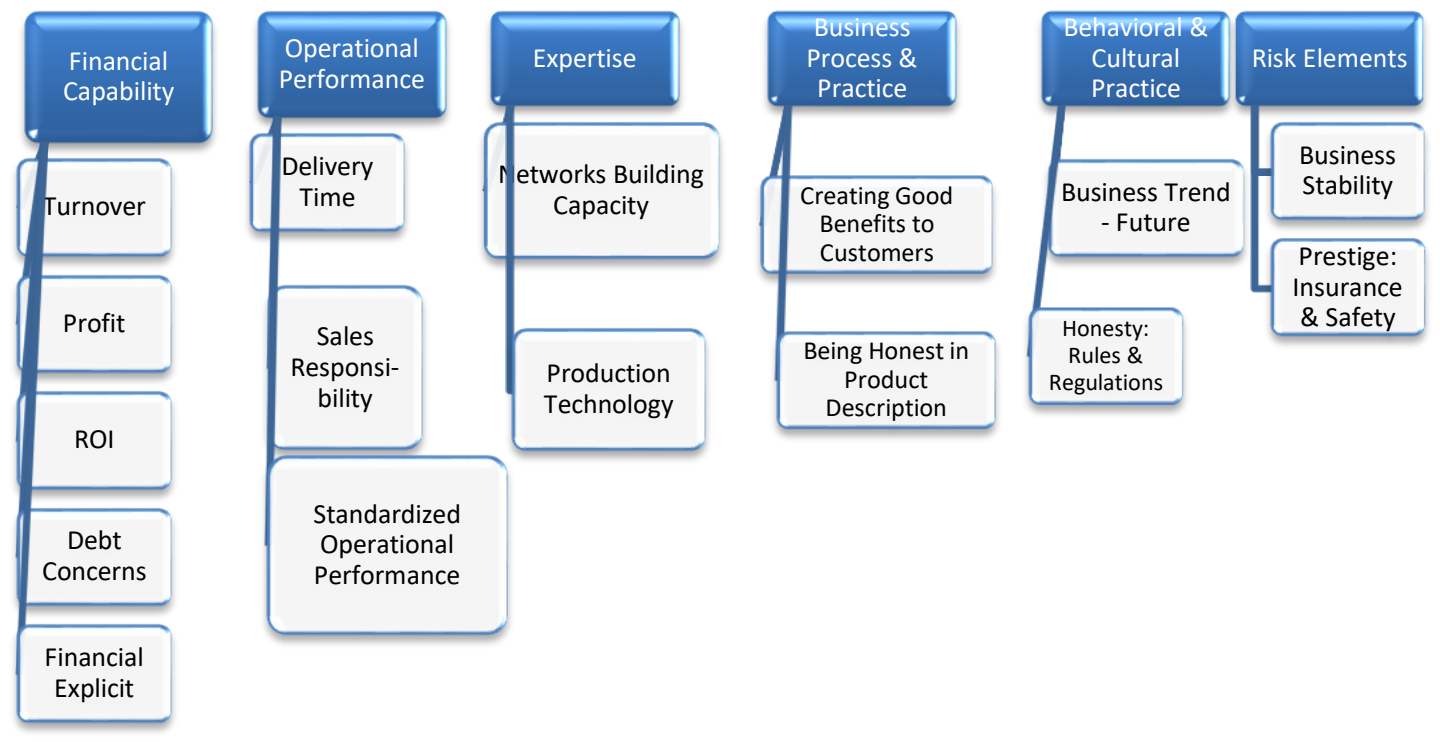

Fig. 3: Evaluating elements model

Table 6: The selection criteria for the suppliers to Big C

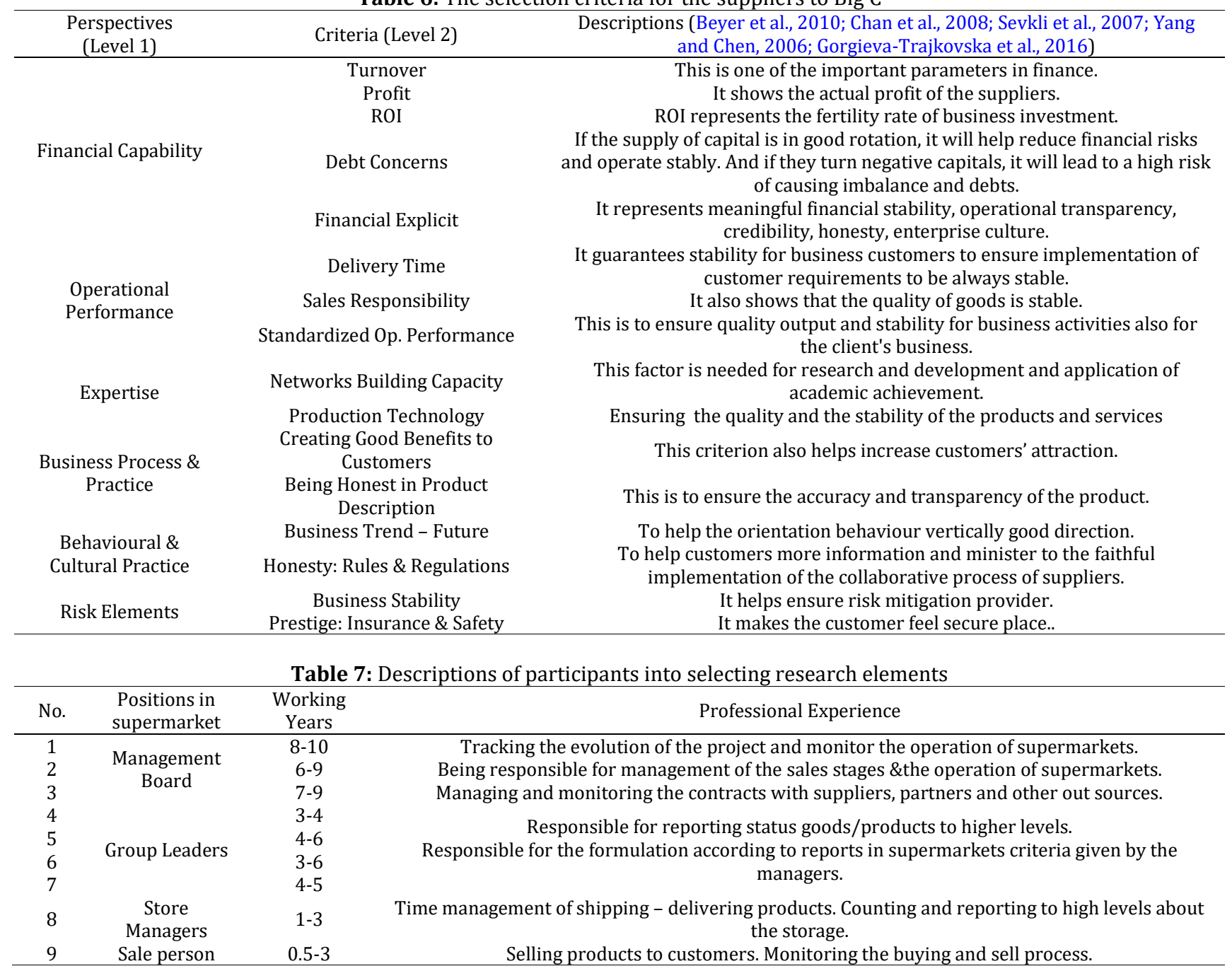

The whole process of this study is present in Fig. 5. There are 9 phases to run, select and analysis based on the applied method - AHP.

\subsubsection{Phase 1: Data collection}

The process of data collection is carried out according to the method of experts: 
Table 8: List of instant coffee suppliers to Big C

\begin{tabular}{cccc}
\hline Number & Suppliers & Websites & Logos \\
\hline 1 & Trung Nguyen Coffee & trungnguyen.com.vn/en/ & g8coffee.com \\
3 & G8 Coffee & en.starbucks.vn \\
4 & Starbucks & NesCafe - Nestle & nestle.com.vn/brands/coffee/nescafe-cafe-viet \\
5 & Vina Café & http://www.vinacafe.com.vn/en & NESCAfE \\
\hline
\end{tabular}

Step 1: based on assessment model has been developed, author use pilot interviews to experts to verify the appropriateness of the 6 main criteria KPI in level one and 16 in level two, together with confirming the identification actual business reality. Step 2: based on the results of step 1 to adjust the model and building surveys/questionnaires (attached in appendix).
Step 3: surveys combined with direct interviewsto each expert. At the request should have over20 experts but by the actual situation should be reduced to 15 experts.

Step 4: collect other data through reports and documents related

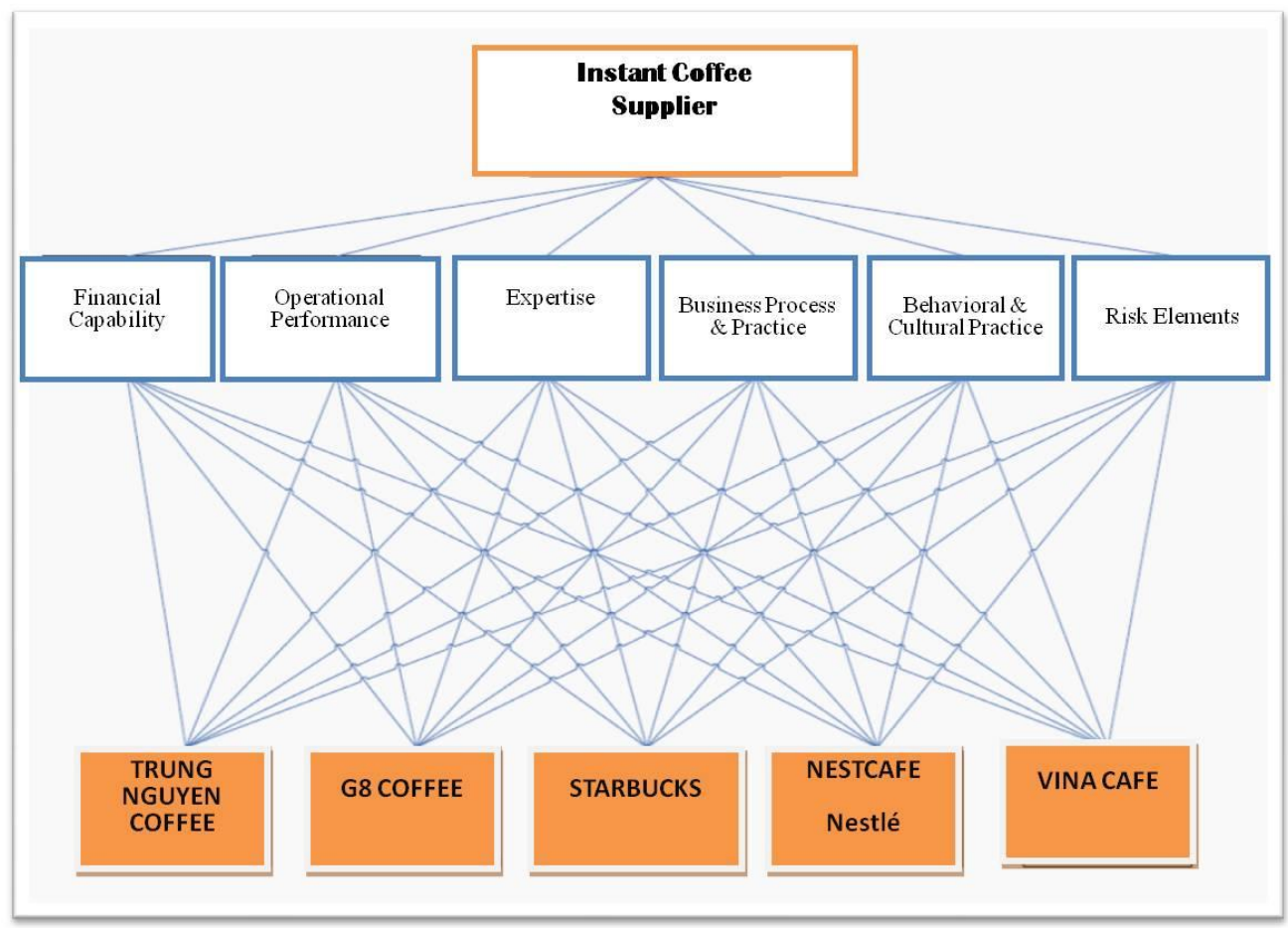

Fig. 4: AHP method to select best supplier of instant coffee

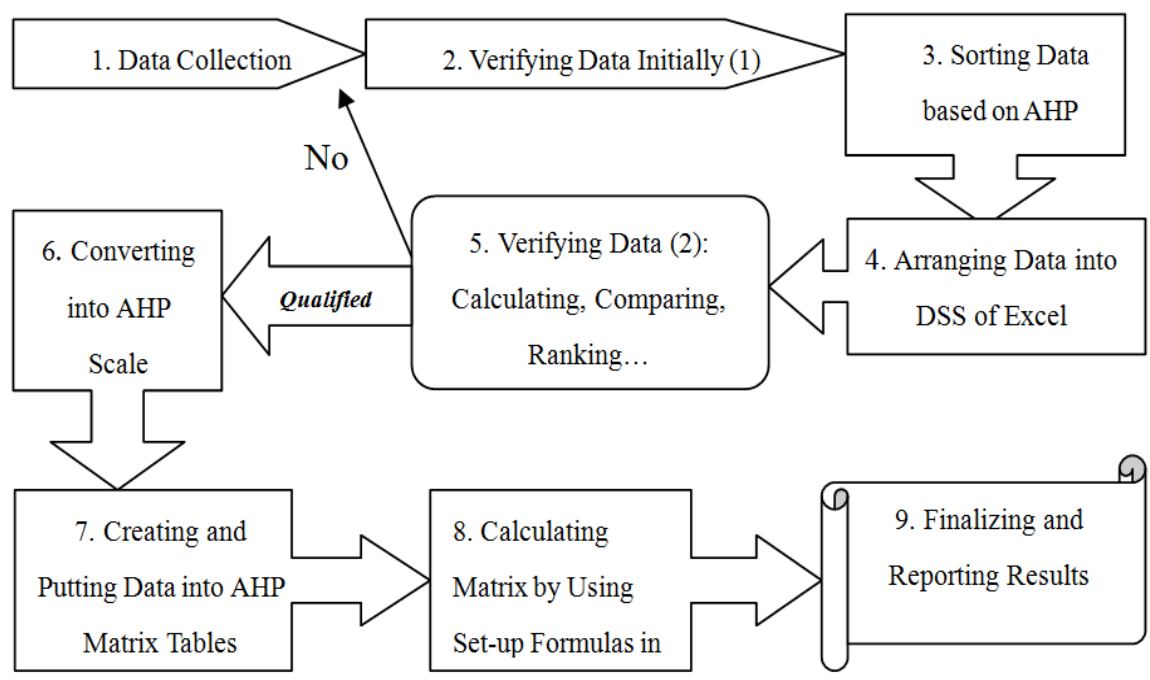

Fig. 5: Flowchart of phases to carry research 


\subsubsection{Phase 2: A batchprocess data}

After collecting a full range of primary data through surveys and interviews with experts' opinions, together with the secondary data through reports: financial, production, performance, etc., these data are processed through the steps of a batch filtering criteria of the main criteria, then filter by the KPI side, verify authenticity versus reality and reliability of the data.

\subsubsection{Phase 3: Sorting data and KPI main criteria of the model}

A batch is classified according to six main criteria, and then they are further classified according to 16 KPI sub-criteria of the model.

Basically, the scale of surveyed items is arranged into a parametric format to do further.

(item i) 9-8-7-6-5-4-3-2-1-2-3-4-5-6-7-8-9 (item j)

0-1-2-3-4-5-6-7-8-9-10-11-12-13-14-15-16

\subsubsection{Phase 4: Enter the model created by Excel}

Excel is as a DSS generator: it is used to construct the computational model, and to handle data for each KPI fitting main criteria in the evaluation model. After setup is complete, the DSS model is to conduct verification of scale, the formula to ensure the appropriateness and scientific. Then, we enter the processed and classified data prior to the DSS model to prepare for phase 5 .

\subsubsection{Phase 5: Data processing secondly}

After entering the data, we conducted calculations, check, and then evaluate for each scale suitably.

\subsubsection{Phase 6: Scale transition to AHP}

AHP method using pair wise comparison scale separately on a scale from one to nine, so after the calculation results ranking suppliers, we must make the transition scales corresponding to the AHP under the own standards of this method. This stage aims to prepare for entering data into the matrix of pair wise comparison at a later stage.

\subsubsection{Phase 7: Creating and putting data into AHP matrix table}

The first boot after the application of the AHP hierarchy drawing assessment model, enter the criteria in a level floor, then to the sub-criteria floor level to level two to $n$, and finally enter choice alternatives. Then enter the data were processed in each pair wise comparison matrices, respectively. Inside is under processing data has been entered into the pair wise comparison matrix between the six main criteria in the evaluation model.

\subsubsection{Phase 8: Calculating matrix by using set-up formulas in Excel}

After we have the AHP tables, we use Excel as a tool to calculate these matrices. Inputting all the data surveyed is a careful step to do to make sure that the calculation is accurate.

\subsubsection{Phase 9: Finalizing and reporting results}

This is the final step of the process. We just see and report results. This will be illustrated carefully in section 4 .

\section{Result analysis}

\subsection{Setting stage}

Comparable data are collected by the method of survey experts through interviews and direct the relevant agencies. Homogeneity index (incon) 0.05 of AHP is satisfactory. The main criteria are comparable bond correlation pairs separate to produce detailed data calculations. Table 9 are typical illustrations for pair wised comparison matrices need to enter the data set gathered from interviews of experts in the relevant industry. There are 23 matrices developed to cater for the processing of the data model and following authors quote a matrix in which to further illustrate this problem:

Denoting: Financial Capability - FC

Operational Performance - OP

Expertise - Exp

Business Process \& Practice - BPP

Behavioral \& Cultural Practice - BCP

Risk Elements - RE

After doing calculation from Table 9, each cell is done by choice divided to the cell total value of the matrix. For example, we have $0.3243=1 / 3.0833$. Then, the weight is the average of each row, which is total divided to the number of criteria.

This weight will be used to calculated the second phase of the matrix, which is illustrated in the below Table 12.

From Table 9, Table 10, and Table 11, we have each criterion value calculation (e.g. $0.3012=1 / 30.1 \%$ ). Then, we come up with SUM and SUM/weight.

SUM/Weight is an important element to calculation lambda max and CI with CR factors, which then are used to test the consistency of the matrix and calculation.

$\lambda \max =\sum \frac{\text { SUM } / \text { Weight }}{\mathrm{n}}=\frac{36.04}{6}=6.01$

$\mathrm{CI}=\frac{(\lambda \max -\mathrm{n})}{(\mathrm{n}-1)}=\frac{(6.01-6)}{(6-1)}=0.015$

$\mathrm{CI}=0.015<0.05$, it shows good consistency of pairwise comparisons. 
$\mathrm{CR}=\frac{|\mathrm{CI}|}{\mathrm{RI}}=\frac{0.015}{1.24}=0.0012$ as mentioned in section 2, there are 6 criteria so $\mathrm{RI}=1.24 . \mathrm{CR}=0.0012=0.12 \%<10 \%$, that means consistent.

Table 9: Matrix of pair wise comparison

\begin{tabular}{|c|c|c|c|c|c|c|}
\hline Criteria & FC & $\mathrm{OP}$ & Exp & BPP & $\mathrm{BCP}$ & $\mathrm{RE}$ \\
\hline $\mathrm{FC}$ & 1 & 2 & 2 & 2 & 4 & 3 \\
\hline $\mathrm{OP}$ & $1 / 2$ & 1 & 1 & $1 / 5$ & 2 & 2 \\
\hline Exp & $1 / 2$ & 1 & 1 & $1 / 3$ & 1 & 2 \\
\hline BPP & $1 / 2$ & 5 & 3 & 1 & 4 & 2 \\
\hline ВCP & $1 / 4$ & $1 / 2$ & 1 & $1 / 4$ & 1 & 1 \\
\hline $\mathrm{RE}$ & $1 / 3$ & $1 / 2$ & $1 / 2$ & $1 / 2$ & 1 & 1 \\
\hline Total & 3.0833 & 10 & 8.5 & 4.2833 & 13 & 11 \\
\hline
\end{tabular}

Table 10: Matrix of pair wise comparison based on Sub-criterion - Turnover

\begin{tabular}{cccccc}
\hline Sub-criterion (Turnover) & Trung Nguyen & G8 Coffee & Starbucks & NesCafe & \multicolumn{2}{c}{ Vina Café } \\
\hline Trung Nguyen & 1 & 8 & 1 & $1 / 5$ & $1 / 9$ \\
G8 Coffee & $1 / 8$ & 1 & 5 & 1 & $1 / 7$ \\
Starbucks & $1 / 4$ & 9 & 5 & $1 / 4$ \\
NesCafe & 1 & 7 & 4 & $1 / 2$ \\
Vina Café & $1 / 2$ & 30 & 14.2 & 2.8111 \\
Total & 2.8750 & & 5.3929 \\
\hline
\end{tabular}

Table 11: Results of first phase calculation

\begin{tabular}{cccccccc}
\hline Criteria & FC & OP & Exp & BPP & BCP & RE & Weight \\
\hline FC & 0.3243 & 0.2000 & 0.2353 & 0.4669 & 0.3077 & 0.2727 & $30.1 \%$ \\
OP & 0.1622 & 0.1000 & 0.1176 & 0.0467 & 0.1538 & 0.1818 & $12.7 \%$ \\
Exp & 0.1622 & 0.1000 & 0.1176 & 0.0778 & 0.0769 & 0.1818 & $11.9 \%$ \\
BPP & 0.1622 & 0.5000 & 0.3529 & 0.2335 & 0.3077 & 0.1818 & $29.0 \%$ \\
BCP & 0.0811 & 0.0500 & 0.1176 & 0.0584 & 0.0769 & 0.0909 & $7.9 \%$ \\
RE & 0.1081 & 0.0500 & 0.0588 & 0.1167 & 0.0769 & 0.0909 & $8.4 \%$ \\
Total & 1 & 1 & 1 & 1 & 1 & 1 & $100 \%$ \\
\hline
\end{tabular}

Table 12: Results of second phase calculation

\begin{tabular}{ccccccccc}
\hline Criteria & FC & OP & Exp & BPP & BCP & RE & SUM & SUM/Weight \\
\hline FC & 0.3012 & 0.2541 & 0.2388 & 0.5794 & 0.3166 & 0.2507 & 1.94 & 6.44 \\
OP & 0.1506 & 0.1270 & 0.1194 & 0.0579 & 0.1583 & 0.1672 & 0.78 & 6.14 \\
Exp & 0.1506 & 0.1270 & 0.1194 & 0.0966 & 0.0792 & 0.1672 & 0.74 & 6.20 \\
BPP & 0.1506 & 0.6351 & 0.3582 & 0.2897 & 0.3166 & 0.1672 & 1.92 & 6.62 \\
BCP & 0.0753 & 0.0635 & 0.1194 & 0.0724 & 0.0792 & 0.0836 & 0.49 & 6.23 \\
RE & 0.1004 & 0.0635 & 0.0597 & 0.1448 & 0.0792 & 0.0836 & 0.37 & 4.41 \\
Total & 0.93 & 1.27 & 1.01 & 1.24 & 1.03 & 0.92 & 6.24 & 36.04 \\
Average & 0.15 & 0.21 & 0.17 & 0.21 & 0.17 & 0.15 & 1.04 & 6.01 \\
\hline
\end{tabular}

From Table 11, we have the weight of Financial Capability is $30.1 \%$ over $100 \%$ of 6 criteria (1-level). Then, we have the weight of each sub-criterion From Table 13. Here, we come to the table showing the percentage of sub-criterion over the whole picture to choose the supplier.

With the same process, from Tables 14 and 15 we can calculate the whole percentage of choice for each supplier under each sub-criterion, which are turnover at $17.7 \%$, profit (6.28\%), ROI (2.59\%), debt concerns (1.55\%), and financial explicit (1.98\%).

These are examples what this study does and gets to have the data from interviews, and surveys of experts.

Table 16 give us the overview about the calculation results from the main criterion to the sub-criteria.

Table 13: Results from matrix of sub-criteria under financial capability

\begin{tabular}{ccccccc}
\hline Financial Capability & Turnover & Profit & ROI & Debt & Financial Explicit & Weight \\
\hline Turnover & 0.6396 & 0.7895 & 0.5714 & 0.4737 & 0.4667 & $58.8 \%$ \\
Profit & 0.0914 & 0.1128 & 0.1905 & 0.3158 & 0.3333 & $20.9 \%$ \\
ROI & 0.1066 & 0.0564 & 0.0952 & 0.1053 & 0.0667 & $8.6 \%$ \\
Debt & 0.0711 & 0.0188 & 0.0476 & 0.0526 & 0.0667 & $5.1 \%$ \\
Financial Explicit & 0.0914 & 0.0226 & 0.0952 & 0.0526 & 0.0667 & $6.6 \%$ \\
Total & 1 & 1 & 1 & 1 & 1 & $100 \%$ \\
\hline \multicolumn{7}{c}{$\mathrm{CR}=0.071=7.1 \%<10 \%$, that means consistent }
\end{tabular}

Table 14: The Global Percentage of each Sub-criterion under Financial Capability

\begin{tabular}{cccc}
\hline Financial Capability & Weight (Local) & Weight of FC & Weight of sub-criterion (Global) \\
\hline Turnover & $58.8 \%$ & $30.1 \%$ & $17.7 \%$ \\
Profit & $20.9 \%$ & $30.1 \%$ & $6.28 \%$ \\
ROI & $8.6 \%$ & $30.1 \%$ & $2.59 \%$ \\
Debt Concerns & $5.1 \%$ & $30.1 \%$ & $1.55 \%$ \\
Financial Explicit & $6.6 \%$ & $30.1 \%$ & $1.98 \%$ \\
Total & $100 \%$ & -- & $30.1 \%$ \\
\hline
\end{tabular}


Table 15: Results from matrix of supplier under sub-criterion -- turnover

\begin{tabular}{|c|c|c|c|c|c|c|}
\hline Sub-criterion (Turnover) & Trung Nguyen & G8 Coffee & Starbucks & NesCafe & Vina Café & Weight \\
\hline Trung Nguyen & 0.3478 & 0.2667 & 0.2817 & 0.3557 & 0.3709 & $32.5 \%$ \\
\hline G8 Coffee & 0.0435 & 0.0333 & 0.0141 & 0.0395 & 0.0265 & $3.1 \%$ \\
\hline Starbucks & 0.0870 & 0.1667 & 0.0704 & 0.0711 & 0.0464 & $8.8 \%$ \\
\hline NesCafe & 0.3478 & 0.3000 & 0.3521 & 0.3557 & 0.3709 & $34.5 \%$ \\
\hline Vina Café & 0.1739 & 0.2333 & 0.2817 & 0.1779 & 0.1854 & $21.0 \%$ \\
\hline Total & 1 & 1 & 1 & 1 & 1 & $100 \%$ \\
\hline
\end{tabular}

Table 16: Global percentage of each supplier under turnover of FC

\begin{tabular}{cccc}
\hline Sub-criterion (Turnover) & Weight (Local) & Weight of sub-criterion (turnover) & Weight of Supplier (Global) \\
\hline Trung Nguyen & $32.5 \%$ & $17.7 \%$ & $5.74 \%$ \\
G8 Coffee & $3.1 \%$ & $17.7 \%$ & $0.56 \%$ \\
Starbucks & $8.8 \%$ & $17.7 \%$ & $1.56 \%$ \\
NesCafe & $34.5 \%$ & $17.7 \%$ & $6.11 \%$ \\
Vina Café & $21.0 \%$ & $17.7 \%$ & $3.72 \%$ \\
Total & $100 \%$ & -- & $17.7 \%$ \\
\hline
\end{tabular}

\subsection{Results and analyses five suppliers by each criterion}

The tables below show the results of data processing which are obtained after running the model evaluation. These data give us an overview of the comparative analysis and evaluation of suppliers between each criterion of the model.

\subsubsection{Evaluation five suppliers by financial capability}

Follow the steps in AHP calculated as described in the literature review. From the pair wise comparison matrices, providers in each sub-criterion of the financial capability criteria including turnover, profit, ROI, debt concerns, and financial explicit are calculated secondary indicators average of each line.

The CR indices of each pair wise comparison among the suppliers are turnover: $C R=0.0402$; profit: $C R=0.0434$; ROI: $C R=0.066$; debt concerns: $\mathrm{CR}=0.0961$, and financial explicit: $\mathrm{CR}=0.0345$. All of them are less than $10 \%$, which means they are consistent in the pair wise comparison.

Table 17 shows the global weight of each supplier of the first criterion - FC. The rankings of each supplier are also shown, which are obviously the first is NesCafe at 9.22\%; Trung Nguyen at second with 7.93\%; closely to Trung Nguyen is Vina Café at 6.75\%; Starbucks and G8 Coffee are sharing the forth and the fifth of the rankings.

Table 17: Global weight of each supplier from sub-criteria under financial capability

\begin{tabular}{|c|c|c|c|c|c|c|c|}
\hline Suppliers & Turnover & Profit & ROI & Debt & Financial Explicit & Sum & Ranking \\
\hline Trung Nguyen & $5.74 \%$ & $0.66 \%$ & $0.70 \%$ & $0.16 \%$ & $0.67 \%$ & $7.93 \%$ & 2 \\
\hline G8 Coffee & $0.56 \%$ & $0.32 \%$ & $0.26 \%$ & $0.58 \%$ & $0.19 \%$ & $1.91 \%$ & 5 \\
\hline Starbucks & $1.56 \%$ & $2.14 \%$ & $0.15 \%$ & $0.15 \%$ & $0.29 \%$ & $4.29 \%$ & 4 \\
\hline NesCafe & $6.11 \%$ & $1.60 \%$ & $0.86 \%$ & $0.34 \%$ & $0.31 \%$ & $9.22 \%$ & 1 \\
\hline Vina Café & $3.72 \%$ & $1.56 \%$ & $0.63 \%$ & $0.32 \%$ & $0.52 \%$ & $6.75 \%$ & 3 \\
\hline Total & $17.7 \%$ & $6.28 \%$ & $2.59 \%$ & $1.55 \%$ & $1.98 \%$ & $30.1 \%$ & -- \\
\hline
\end{tabular}

\subsubsection{Evaluation five suppliers by operational performance and expertise}

Table 18 and Table 19 show the results of weighting five suppliers. The results prove the significant values with CR at 0.0506 for 'Delivery
Time'; CR at 0.0097 for 'Sales Responsiveness' and so on.

At the sub-criteria under operational performance, the rankings are Trung Nguyen at the first place, Vina Cafe second, Starbucks in the third place, NesCafe in the fourth place and lastly G8 Coffee.

Table 18: The global percentage of each sub-criterion under operational performance

\begin{tabular}{|c|c|c|c|c|c|c|}
\hline $\begin{array}{c}\text { Operational } \\
\text { Performance } \\
\end{array}$ & Delivery Time & Sales Resp & Standardized OP & $\begin{array}{l}\text { Weight } \\
\text { (Local) }\end{array}$ & $\begin{array}{l}\text { Weight of } \\
\text { OP } \\
\end{array}$ & $\begin{array}{l}\text { Weight of sub- } \\
\text { criterion (Global) }\end{array}$ \\
\hline Delivery Time & 0.7636 & 0.8235 & 0.6667 & $75.1 \%$ & $12.7 \%$ & $9.54 \%$ \\
\hline Sales Resp & 0.1091 & 0.1176 & 0.2222 & $15.0 \%$ & $12.7 \%$ & $1.90 \%$ \\
\hline Standardized OP & 0.1273 & 0.0588 & 0.1111 & $9.9 \%$ & $12.7 \%$ & $1.26 \%$ \\
\hline Total & 1 & 1 & 1 & $100 \%$ & -- & $12.7 \%$ \\
\hline
\end{tabular}

Table 19: Global Weight of each Supplier from Sub-criteria under Operational Performance

\begin{tabular}{|c|c|c|c|c|c|}
\hline Suppliers & Delivery Time & Sales Resp. & Standardized OP & Sum & Ranking \\
\hline Trung Nguyen & $3.68 \%$ & $0.31 \%$ & $0.31 \%$ & $4.30 \%$ & 1 \\
\hline G8 Coffee & $0.53 \%$ & $0.11 \%$ & $0.15 \%$ & $0.79 \%$ & 5 \\
\hline Starbucks & $1.02 \%$ & $0.88 \%$ & $0.27 \%$ & $2.17 \%$ & 3 \\
\hline NesCafe & $1.65 \%$ & $0.13 \%$ & $0.11 \%$ & $1.89 \%$ & 4 \\
\hline Vina Café & $2.66 \%$ & $0.47 \%$ & $0.42 \%$ & $3.55 \%$ & 2 \\
\hline Total & $9.54 \%$ & $1.90 \%$ & $1.26 \%$ & $12.7 \%$ & -- \\
\hline
\end{tabular}


Considering this criterion of core competencies, we have two pair wise comparison matrices provided in the two sub-criteria -- building networks capacity and production technology. After running the model results, we gathered in Table 20.

Table 20: The global percentage of each sub-criterion under expertise

\begin{tabular}{cccccc}
\hline Expertise & $\begin{array}{c}\text { Networks Building } \\
\text { Capacity }\end{array}$ & Production Tech. & $\begin{array}{c}\text { Weight } \\
\text { (Local) }\end{array}$ & $\begin{array}{c}\text { Weight of } \\
\text { Exp. }\end{array}$ & $\begin{array}{c}\text { Weight of sub- } \\
\text { criterion (Global) }\end{array}$ \\
\hline Networks Building Capacity & 0.6667 & 0.6667 & $66.7 \%$ & $11.90 \%$ & $7.93 \%$ \\
Production Tech. & 0.3333 & 0.3333 & $33.3 \%$ & $11.90 \%$ & $3.97 \%$ \\
Total & 1 & 1 & $100 \%$ & -- & $11.90 \%$ \\
\hline
\end{tabular}

Table 21 shows the result of five suppliers. The total percentage for all is $11.9 \%$ due to the weight of the criterion - EXPERTISE. Apparently, STARBUCKS is coming at the first place at $3.89 \%$ of the two subcriteria, followed by NesCafe at $2.71 \%$.

At the last place, G8 Coffee is just at $0.85 \%$.

Table 21: Global weight of each supplier from sub-criteria under expertise

\begin{tabular}{ccccc}
\hline Suppliers & Networks Building Capacity & Production Tech. & Sum & Ranking \\
\hline Trung Nguyen & $0.93 \%$ & $1.25 \%$ & $2.18 \%$ & 4 \\
G8 Coffee & $0.46 \%$ & $0.39 \%$ & $0.85 \%$ & 5 \\
Starbucks & $3.22 \%$ & $0.67 \%$ & $3.89 \%$ & 1 \\
NesCafe & $2.22 \%$ & $0.49 \%$ & $2.71 \%$ & 2 \\
Vina Café & $1.10 \%$ & $1.16 \%$ & $2.26 \%$ & 3 \\
Total & $7.93 \%$ & $3.97 \%$ & $11.9 \%$ & -- \\
\hline
\end{tabular}

Moreover, the elements to evaluate this arrangement and selection of experts from the interviews and survey are CRs of sub-criteria, which are Networks Building Capacity: CR=0.0189; Production Tech. CR $=0.0591$. Noticeably, all their CRs are less than $10 \%$ that means they are consistent and acceptable.

\subsubsection{Evaluation five suppliers by business process \& practice}

The next step we consider two sub-criteria including creating the best value for our customers and share honest information about products (advantages and disadvantages, appropriate), forecasts of criteria Method business. From three pair wise comparison matrices will be two matrices calculated average flow as follows.

According experts, the criterion -- Business Process \& Practice is considered to be an important element at $29 \%$. Thus, the suppliers need to be very careful in creating "Benefits to Customers" and to be "Honesty in Product Description".

These two sub-criteria are at the same level of importance to each other $(50 \%-50 \%$ for local weight) and $14.5 \%$ at global weight (Table 22).

Table 22: The global percentage of each sub-criterion under business process \& practice

\begin{tabular}{|c|c|c|c|c|c|}
\hline Expertise & $\begin{array}{l}\text { Benefit to } \\
\text { Customers }\end{array}$ & Honest in Product & Weight (Local) & Weight of BPP & $\begin{array}{l}\text { Weight of sub-criterion } \\
\text { (Global) }\end{array}$ \\
\hline Benefit to Customers & 0.5000 & 0.5000 & $50.0 \%$ & $29 \%$ & $14.50 \%$ \\
\hline Honest in Product & 0.5000 & 0.5000 & $50.0 \%$ & $29 \%$ & $14.50 \%$ \\
\hline Total & 1 & 1 & $100 \%$ & -- & $29 \%$ \\
\hline
\end{tabular}

Table 23 shows the results of suppliers' ranking, which clearly states at $1^{\text {stand }} 2^{\text {nd }}$ belongs to Vina Café and Trung Nguyen. The last place is for Starbucks - the new comer to Vietnamese market of instant coffee.
These criteria are expressing the significance so that their CRs are also significantly consistent -Benefits to Customers: $\mathrm{CR}=0.0033$; Honest in Product Description; CR=0.0216.

Table 23: Global weight of each supplier from sub-criteria under business process $\&$ practice

\begin{tabular}{ccccc}
\hline Suppliers & Benefits to Customers & Honest in Product & Sum & Ranking \\
\hline Trung Nguyen & $5.24 \%$ & $2.48 \%$ & $7.72 \%$ & 2 \\
G8 Coffee & $1.79 \%$ & $3.74 \%$ & $5.53 \%$ & 3 \\
Starbucks & $0.70 \%$ & $2.16 \%$ & $2.86 \%$ & 5 \\
NesCafe & $1.66 \%$ & $3.26 \%$ & $4.92 \%$ & 4 \\
Vina Café & $5.11 \%$ & $2.85 \%$ & $7.96 \%$ & 1 \\
Total & $14.50 \%$ & $14.50 \%$ & $29 \%$ & -- \\
\hline
\end{tabular}

\subsubsection{Evaluation five suppliers by behavioral and cultural practice}

By this criterion, the nature of assessment in favor of cultural factors include business culture and cultural honest. Therefore, promised many changes in the rankings of suppliers. It comes from the pair wise comparison matrices calculated the average value for the line to assess behavior analysis \& cultural factor criteria.

Table 24 and Table 25 show the ranking of five suppliers: Trung Nguyen, G8, Starbucks, NesCafe, 
Vina Café in the coffee market. According to the percentage indices, Trung Nguyen and Starbucks account equally from the market dividend (1.87\%), while Vina Café and G8 rank secondly (percentage nearly $1.64 \%$ ). NesCafe has only $1.18 \%$ of market dividend.

Table 24: The global percentage of each sub-criterion under behavioral \& cultural practice

\begin{tabular}{|c|c|c|c|c|c|}
\hline Expertise & Business Trend & Rules \& Regulations & Weight (Local) & Weight of BCP & $\begin{array}{l}\text { Weight of sub-criterion } \\
\text { (Global) }\end{array}$ \\
\hline Business Trend & 0.8000 & 0.8000 & $80.0 \%$ & $7.9 \%$ & $6.32 \%$ \\
\hline Rules \& Regulations & 0.2000 & 0.2000 & $20.0 \%$ & $7.9 \%$ & $1.58 \%$ \\
\hline Total & 1 & 1 & $100 \%$ & -- & $7.9 \%$ \\
\hline
\end{tabular}

Table 25: Global weight of each supplier from sub-criteria under behavioral \& cultural practice

\begin{tabular}{|c|c|c|c|c|}
\hline Suppliers & Business Trend & Rules \& Regulations & Sum & Ranking \\
\hline Trung Nguyen & $1.60 \%$ & $0.27 \%$ & $1.87 \%$ & 1 \\
\hline G8 Coffee & $0.94 \%$ & $0.40 \%$ & $1.34 \%$ & 4 \\
\hline Starbucks & $1.42 \%$ & $0.45 \%$ & $1.87 \%$ & 1 \\
\hline NesCafe & $0.94 \%$ & $0.24 \%$ & $1.18 \%$ & 5 \\
\hline Vina Café & $1.42 \%$ & $0.22 \%$ & $1.64 \%$ & 3 \\
\hline Total & $6.32 \%$ & $1.58 \%$ & $7.9 \%$ & -- \\
\hline
\end{tabular}

The consistent criteria are all below $10 \%$ which are Business Trend: CR=0.0261; Rules \& Regulations; $\mathrm{CR}=0.0358$.

\subsubsection{Evaluation five suppliers by risk elements}

This is the final criterion for evaluating models of this essay. And it includes two sub-criteria is financial stability of the business and reliability.

Table 26 analyzes the stable position of five suppliers in the instant coffee market, which includes the percentage indices of business stability and prestige, and also contains the ranking between businesses as well. With suitable business strategy and good product quality, Vina Café and Trung Nguyen coffee always keep their perfect prestige into domestic customers' perception, so they keep the best ranking and have indices of business prestige nearly $1.78 \%$ and $1.91 \%$ respectively. Whereas, international brands of Starbuck and Nes Café occupies the third and fourth positions of business prestige into Vietnamese coffee market with the lower indices $(0.36 \%$ and $1.12 \%)$. Comparing to the above four suppliers, G8 coffee has lowest index of business stability and prestige, which is $0.14 \%$ and $0.43 \%$ respectively (Table 27 ).

Table 26: The global percentage of each sub-criterion under risk elements

\begin{tabular}{|c|c|c|c|c|c|}
\hline Expertise & Business Stability & Prestige & Weight (Local) & Weight of RE & $\begin{array}{c}\text { Weight of sub- } \\
\text { criterion (Global) }\end{array}$ \\
\hline Business Stability & 0.3333 & 0.3333 & $33.3 \%$ & $8.4 \%$ & $2.80 \%$ \\
\hline Prestige & 0.6667 & 0.6667 & $66.7 \%$ & $8.4 \%$ & $5.60 \%$ \\
\hline Total & 1 & 1 & $100 \%$ & -- & $8.4 \%$ \\
\hline
\end{tabular}

Table 27: Global weight of each supplier from sub-criteria under risk elements

\begin{tabular}{|c|c|c|c|c|}
\hline Suppliers & Business Stability & Prestige & Sum & Ranking \\
\hline Trung Nguyen & $0.76 \%$ & $1.78 \%$ & $2.54 \%$ & 2 \\
\hline G8 Coffee & $0.14 \%$ & $0.43 \%$ & $0.57 \%$ & 5 \\
\hline Starbucks & $0.39 \%$ & $0.36 \%$ & $0.75 \%$ & 4 \\
\hline NesCafe & $0.78 \%$ & $1.12 \%$ & $1.90 \%$ & 3 \\
\hline Vina Café & $0.73 \%$ & $1.91 \%$ & $2.64 \%$ & 1 \\
\hline Total & $2.80 \%$ & $5.60 \%$ & $8.4 \%$ & -- \\
\hline
\end{tabular}

Moreover, this criterion is also done with the consistence of experts' ideas when their subcriteria's CRs are below 10\% -- Business Stability: $\mathrm{CR}=0.0693$; Prestige; $\mathrm{CR}=0.051$.

\subsection{Best choice of suppliers}

After respectively calculating, analysis and evaluating of suppliers through each sub-criterion of six main criteria in Balanced Scorecard of AHP model, we have been solving the second floor of AHP hierarchy. Now is the implementation of steps to the first floor properties of the ladder consists of six main criteria evaluation model.

Table 28 shows the number of evaluation points each supplier according to the results of each model run sub-criteria are calculated as in the previous section form the matrix on the left. And $6 \times 1$ matrix on the right is the local index of the main criteria in each model.

This is the final calculation results which are obtained after running the data through the two floors of the criteria assessment model according to the method of AHP. The percentages are of suppliers shown in the table. Based on these values, we can rank as well as further analysis of the selected alternatives. Plus we can evaluate each provider. Besides, to compare the degree of difference between the alternatives Big C can make a decision in choosing the best suppliers and the most suitable.

Figs. 6 and 7 summarize the final decision of selecting right partner after applying AHP method. In Fig. 6, we can see the changes of percentage of suppliers by criteria. Nescafe's percentages have 
change widely from FC to RE, finally it gets $24.8 \%$ of the pie chart. While Trung Nguyen stays the same situation, and it come to the first position at $26.54 \%$. G8 coffee is less percent at only $11 \%$.

Table 28: Summary of analysis and final ranking

\begin{tabular}{|c|c|c|c|c|c|c|c|c|}
\hline Suppliers & $\mathrm{FC}$ & $\mathrm{OP}$ & Exp & BPP & $\mathrm{BCF}$ & $\mathrm{RE}$ & Sum & Ranking \\
\hline Trung Nguyen & $7.93 \%$ & $4.30 \%$ & $2.18 \%$ & $7.72 \%$ & $1.87 \%$ & $2.54 \%$ & $26.54 \%$ & 1 \\
\hline G8 Coffee & $1.91 \%$ & $0.79 \%$ & $0.85 \%$ & $5.53 \%$ & $1.34 \%$ & $0.57 \%$ & $10.99 \%$ & 5 \\
\hline Starbucks & $4.29 \%$ & $2.17 \%$ & $3.89 \%$ & $2.86 \%$ & $1.87 \%$ & $0.75 \%$ & $15.83 \%$ & 4 \\
\hline NesCafe & $9.22 \%$ & $1.89 \%$ & $2.71 \%$ & $4.92 \%$ & $1.18 \%$ & $1.90 \%$ & $21.82 \%$ & 3 \\
\hline Vina Café & $6.75 \%$ & $3.55 \%$ & $2.26 \%$ & $7.96 \%$ & $1.64 \%$ & $2.64 \%$ & $24.80 \%$ & 2 \\
\hline Total & $30.10 \%$ & $12.70 \%$ & $11.89 \%$ & $28.99 \%$ & $7.90 \%$ & $8.40 \%$ & $99.98 \%$ & -- \\
\hline
\end{tabular}

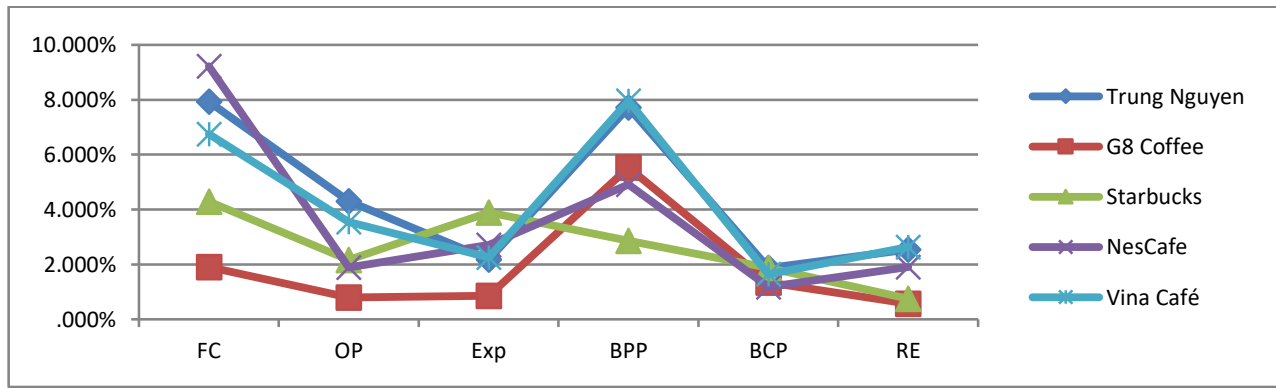

Fig. 6: Weights of suppliers

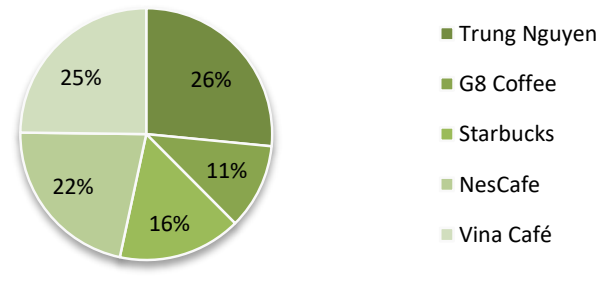

Fig. 7: Percentage of final selection

\section{Discussion and managerial implications}

After the integrating of Delphi and AHP process in vendor Instant coffee industry's Big C, we see that are more restrictive of the current review process of such enterprises rather qualitative, lack of objectivity, mainly depending on experience and sense of decision makers.

The results from the model are evaluated using the method of AHP quantification. AHP can compare the tiniest differences between providers through the numbers, charts and graphs. The results of detailed calculations to each level of the ladder system provide multi-faceted perspective. Strong ability to synthesize the components of the hierarchy and logic algorithms are not too complicated, but also help managers can examine each aspect and see the overview are all issues are considered.

In an organization that has always existed three important lines: The first line of communication throughout the system, the second is financial flows, also known simply as cash flow, and finally the material flow. Purchasing is one of the important tasks of the business because it is responsible for the physical input line of the organization. Increasing awareness of purchasing should be advanced position and its role in the enterprise is increasing. Most organizations now recognize closely related to purchasing strategy should the company access to parts purchasing increasingly more difficult.
Information security requirements for these departments are increasingly stringent.

The process of evaluation and selection of suppliers has long held bias in a qualitative sense, dependent on experience and emotions of those who have related responsibilities. Therefore, it is necessary to apply the typical methods such as quantitative analysis of this process - AHP presented in this study. With the aim of increasing the computational content of the evaluation process suppliers, especially the comparison of suppliers in the same industry as AHP has shown. This enables the analysis of all the providers and more scientific. Thus, this study would help the facility managers ensure objectivity to the reasonable decision.

Through the application of analytical methods to process steps or methods to compare providers evaluate other qualitative factors could improve the current process of purchasing Big $\mathrm{C}$ more objective and scientific. Thanks to the AHP, the staff can choose to be the purchasing supply high quality goods with low price coming with the attractive added value such as: high reputations, professional services, are much credit, good culture, etc. The main evaluation criteria have been quantified to ensure that most of the stages in the purchasing process. When selecting business partners are well supplied, all stages in the process of purchasing them achieve flawless collaboration.

\section{Limitations and future research}

In this paper, we have not yet deepened data sources since purchasing data sources is an issue related to strategic information to be accessed. In addition, Big $\mathrm{C}$ has rules limiting data sharing so the materials needed to get tougher.

This study utilizes the interview method access the expert groups and questionnaire surveys with data collected to be slightly biased and subjective experience. The data primarily comes from the 
documents and reports out there, not yet homogeneous. Years missing data so that comparisons between providers and become limp. The process measurement data collected are processed and applied scales also unsettled. The comparison between the criteria in suppliers has not yet met the stringent requirements of the equivalent. The transformation scales to scales AHP has many limitations.

It is possible to dig more theoretical model further evaluation. There are many criteria that can be used for model assessment. Every type of business and every business will have specific criteria in accordance with the individual's typical enterprise. It is important to note build an assessment model provider in accordance with industry characteristics and distinctions of the business. It should be tried to reach deep to the data source to the enterprise purchasing the topic under direction of this form of anonymous real close to reality than now.

\section{Conclusion}

After a long process of calculation based on Delphi and AHP, we have chosen the final supplier according expert's interview. The results have been stated in section 4 that Trung Nguyen is the most potential candidate to be the main supplier of instant coffee to Big C. The next priority should be Vina Café, NesCafe, Starbucks and G8 Coffee.

By this paper, author would contribute to the purchasing process of the supermarket, in general, and the special case of Big $\mathrm{C}$ a very modern model to apply, then to choose the right partner, not only for instant coffee industry but it can be applied for a lot of industries to the supermarkets.

\section{References}

Baily PJ, Farmer D, and Jessop D (2005). Purchasing principles and management. Pearson Education, London, UK.
Beyer A, Cohen DA, Lys TZ, and Walther BR (2010). The financial reporting environment: Review of the recent literature. Journal of Accounting and Economics, 50(2): 296-343.

Chan FT, Kumar N, Tiwari M.K, Lau HCV, and Choy KL (2008). Global supplier selection: A fuzzy-AHP approach. International Journal of Production Research, 46(14): 38253857.

Chavan M (2009). The balanced scorecard: A new challenge. Journal of management development, 28(5): 393-406.

Faisal MN and Banwet DK (2008). Analysing alternatives for information technology outsourcing decision: An analytic network process approach. International Journal of Business Information Systems, 4(1): 47-62.

Gorgieva-Trajkovska O, Nikoloski K, Koleva B, and Georgieva Svrtinov V (2016). The role of corporate governance in transition economies: Contribution and development. Constantin Brâncuşi University, Târgu Jiu, Romania. Available online at: http://eprints.ugd.edu.mk/id/eprint/16666

Hawkins DI, Mothersbaugh DL, and Best RJ (2013). Consumer behavior: Building marketing strategy. McGraw-Hill, New York, USA.

Lysons K (1996). Purchasing. Macdonald \& Evans Ltd, London, UK.

Pope JA, Lane WR, and Stein J (2012). A multiple-attribute decision model for retail store location. Southern Business Review, 37(2): 15-25.

Saaty TL (1999). Fundamentals of the analytic network process. In the $5^{\text {th }}$ Conference on the Analytic Hierarchy Process, Kobe, Japan: 12-14. Available online at: https://pdfs. semanticscholar.org/1d82/e1d88b007dc91b2269f44a9360b 400d5ae68.pdf

Saaty TL (2000). Fundamentals of decision making and priority theory with the analytic hierarchy process. RWS Publications, Pittsburgh, Pennsylvania, USA.

Sevkli M, Lenny Koh SC, Zaim S, Demirbag M, and Tatoglu E (2007). An application of data envelopment analytic hierarchy process for supplier selection: A case study of BEKO in Turkey. International Journal of Production Research, 45(9): 1973-2003.

Verma R and Pullman ME (1998). An analysis of the supplier selection process. Omega, 26(6): 739-750.

Yang CC and Chen BS (2006). Supplier selection using combined analytical hierarchy process and grey relational analysis. Journal of Manufacturing Technology Management, 17(7): 926-941. 